\title{
Influence of Paralegal Medical Services on Children's Right to Education in Kenya, A Case of Migori County
}

\author{
Rebecca Adawo, Paul Amoloh Odundo, John Kamau Mwangi, Ganira Khavugwi Lilian \\ School of Education, College of Education and External Studies, Department of Educational Communication and Technology, University of \\ Nairobi, Nairobi, Kenya
}

\section{Email address:}

adaworebecca@gmail.com (R. Adawo),odundopaul@yahoo.com (P. A. Odundo),jnkamau@uonbi.ac.ke (J. K. Mwangi), kganira@yahoo.com (G. K. Lilian)

\section{To cite this article:}

Rebecca Adawo, Paul Amoloh Odundo, John Kamau Mwangi, Ganira Khavugwi Lilian. Influence of Paralegal Medical Services on Children's Right to Education in Kenya, A Case of Migori County. International Journal of Elementary Education.

Vol. 5, No. 3, 2016, pp. 28-39. doi: 10.11648/j.ijeedu.20160503.11

Received: February 2, 2016; Accepted: March 15, 2016; Published: August 17, 2016

\begin{abstract}
Paralegal medical service plays a major role in protecting children right to education. Provision of adequate paralegal medical services promotes children's education. Most studies in Kenya have been interested on health and education of children without examining influence of medical services offered by paralegals to protect children's right to education. The entire sampling matrix yielded a total sample size of 348 respondents comprising the paralegals and recipients in the study. Questionnaires and interview schedules were used for data collection. A combination of simple random sampling technique and purposive sampling procedures were used to select respondents for the study. Descriptive analysis was produced using statistical package for social sciences (SPSS) while qualitative analysis considered inferences made from views and opinions of respondents. Results showed that traditional birth attendants were the most significant paralegals, followed by NGOS and individual /private paralegals respectively. The study further found that paralegals offered quality but inadequate medical services to protect children right to education. This is due to, poor economic levels and low education. The study concluded that, paralegal medical services supplemented well the inadequate health services provided by the government, not accessible to most children.
\end{abstract}

Keywords: Paralegal, Medical Services, Children Education

\section{Introduction}

A paralegal is a person qualified by education, training or work experience to perform legal task requiring some knowledge of the law and legal procedure (Warner, 2014). Professional paralegals vary greatly between states due to the fact that some states encompass non-lawyers doing legal work regardless of whom they do it for (Green, 1993). Similarly, Cowley (2010) contend that although most jurisdictions recognize paralegals to a greater or lesser extent, there is no international consistency as to definition job role, status, terms and conditions of employment, training regulation or anything else and so any jurisdiction must be looked at individually. ${ }^{1}$ In this regard, the paralegals offer

1 http://en.wikipedia.org/wiki/paralegal\#referance medical services to ensure children are sustained in good health to protect their right to education.

Enjoyment of the highest attainable standard of health is one of the fundamental rights of every child without distinction of race, religion, political belief, economic or social condition (WHO, 2014). United Nations International Children's Education Fund (UNICEF, 2006) paralegal reports that ECE continues to be neglected in the education sector. However, countries like United Kingdom have established national framework for provision of health services such as working with communities and families to invest critically in vaccines and provide cold rooms, which keep vaccine safe at the right temperature. Besides, WHO and UNICEF, (2011) finances new affordable vaccines for world's poorest countries. Poor health among children reduces time spent in school therefore, hindering education.

In contrast to this WHO and UNICEF (2006) paralegal 
conduct joint campaign on breast feeding, growth monitoring, immunization and oral rehydration therapy arguing that, unless injury prevention is included in such programs children grow up and are subjected to injuries. This may impact negatively on large investment in immunization, nutrition, maternal and child healthcare. In agreement to this, Singh regional director of UNICEF East Asia and Pacific argue that, for us to meet the millennium development goal to improve children's health and reduce child mortality, it is imperative that we take action to address the causes of childhood injury (MC Michael, 2000). Prevention and treatment of child injury is paramount to quality ECE hence should be included as a prerequisite element in all health services provided to children. WHO (2014), report reveals that African Humanitarian Action paralegal provide basic preventative and curative services with a focus on most vulnerable children in most countries in Africa such as Cameroon, Ethiopia, Sudan just to mention but a few. In addition, paralegal integrates mental health care throughout identifying and treating mental health problems as well as providing psychological support services. More still, Adawo, (2015), assert that children who have had serious health issues can still be assisted to continue with education. In Kenya the government demonstrated commitment to the wellbeing of young children by signing various global policy frameworks including United Nations Convention on the rights of the child (UNCRC, 1989), and Education Forum held in Dakar Senegal (2000) among others. The government translated all these international initiatives into national targets hence involvement of paralegals in provision of services to cater for diverse needs of children ( $\mathrm{MOH}, 2005)$. Paralegal medical service provision increases status of infants and children in health consequently protecting their education. Onditi paralegal (2014) in conjunction with Ombo Catholic church in Migori county provide medical care to OVC, sensitization services, referrals for HIV testing and treatment in addition to acting as a means for psycho-social support offering solace and coping techniques. Children in poor health condition have less interest in education resulting to truancy, absenteeism and drop outs. In this regard, provision of medical services has a great impact on children's education. The study found a positive relationship between paralegal medical services and children's right to education. This paper therefore presents findings of a study that investigated among others the influence of paralegal medical services on protection of children's right to education.

\subsection{Statement}

Provision of medical services to protect children's right to education has been a concern and a shared responsibility among parents, community, private sector and the government. In pursuit of this, African Humanitarian Action (AHA, 2014) paralegal through Integrated AIDs Program (IAP) provide mass immunization, well- child clinics, prevention of mother to child transmission, training of midwives and traditional birth attendants to reduce maternal and child mortality. Moreover, the paralegal train community volunteers to provide OVC with home based care, improve access to voluntary counseling and testing as well as treatment of opportunistic infections (WHO, 2014). Nevertheless, medical services are still inadequate as survey report (KDHS, 2003), Wambiri and Ngugi (2006) reveal declining health status of infants and children, welfare and segmented provision of services across different sectors by diverse stakeholders all undermining children's right to education. A similar study show that poor children have little interaction with healthcare personnel outside of vaccination and clinic visits for acute conditions in both rural and urban environment (CARE, 2005). Worse Still, study of CARE (2001) paralegal in Kenya revealed that participation of CBOs, FBOs, and private sector in HIV/AIDS messages communicated by implementing agencies have not been harmonized resulting to poor children's health. In instances, where there is adequate provision of paralegal medical services, children's academic achievements are high, low drop and outstanding productivity is high (AMREF, 2002). However, inadequate provision of medical services to children impact negatively on physical and growth development resulting to mental retardation. Mentally retarded child has low intelligent quotient hence cannot participate competently in most activities resulting to low educational achievements. It is in this view that the proposed study sought to investigate influence of paralegal medical services on children's right to education.

\subsection{Purpose and Objective}

The purpose of this study was to investigate influence of paralegal medical services on protection of children's right to education. The findings of this study are likely to be of immense value to the government, NGOs, community and educational planners. Influence of paralegal medical services on children's education will help the government realize the importance of paralegals. This will lead to improvement of strategies for strengthening paralegal health services to ensure protection of children's education. Specifically the study was conducted to determine the effect of paralegal medical services on children's education.

\section{Review of Related Literature}

\subsection{Introduction}

The purpose of this paper was to establish the study foundation, explore views of different studies and to provide a framework within which primary data was to be contextualized and interpreted. It further indicated theoretical basis of paralegal medical services and conceptual framework that encompassed major variables of the study and their influence on children's right to education.

\subsection{Paralegal Medical Services and Children's Right to Education}

Studies done by CARE confirmed that in North Carolina, Advocate for Children Services Paralegal (2009) provides 
quality medical care, healthy environment, adequate food, clothing and shelter to protect children's health. In addition the paralegal offers a safe permanent family and necessary social services to all children regardless of race, class, gender, disability or immigration status (Raleigh, 2014). Good health reduces absenteeism in children and improves educational performance. Jolly (2007) concurs that for young children's health to improve communities need access to quality health clinics, safe water and sanitation.

In Rwanda a model for community based care for orphans and vulnerable children illustrates a successful community based project which incorporates local authorities into an advisory board, increasing local ownership and sensitivity to child rights. CARE paralegal's 5 x 5 model is focused on establishing formal links with clinics and hospitals in order to bring preventive services to ECD centers and communities and build referral mechanisms for HIV testing and treatment (CARE, 2005). Besides, ECD practitioners are also informed of options available for testing and treatment, in order to discuss options with parents and caregivers to ensure young children receive assistance needed to protect education (CARE, 2004). Moreover, establishing policies around vaccinations within ECD centers and keeping records of children's vaccination statuses are fundamental to CARE paralegal's $5 \times 5$ model.

In rural areas, where access to health service is often limited, linking with existing resources as well as identifying and mobilizing community health workers provides children and guardians with better health care options (CARE, 2005). Access to treatment sites enhances routine health screening which help in identifying children in need of referrals for further intervention to ensure good health condition for quality education. However, WHO (2015) paralegal in contrast emphasizes that safe and sufficient drinking water along with adequate sanitation should be provided to eradicate poverty and hunger. These combat infectious diseases which would otherwise interfere with children's education.

In Madagascar, Global Alliance for Vaccine and Immunization (GAVI, 2011) in conjunction with the World Health Organization (WHO, 2011) and UNICEF (2011) paralegal finances new affordable vaccines for the world's poorest countries. Besides, Gavi Paralegal promotes safe injections and introduces new preventive childhood killers including tetanus, diphtheria and a new vaccine against pneumococcal disease (Nossal, 2000). Good health enhances children's participation in class activities, which results to improvement of education. Studies undertaken by (UNESCO, 2000) and (World Bank, 2003) concur that many children still experience poor health which reduces learning for a variety of reasons including low daily attendance and less efficient learning per day spent in school.

Action in the community environment paralegal (ACE, 2007) in Tanzania encourages children to become active agents of change, offer educational services that protect children from HIV and AIDs infection, offer training services to head teachers with a specific focus on HIV/AIDS as well as ensure provision of medication services. Findings from the paralegal (ACE, 2007) identifies vulnerable children whose rights are abused, prevents water bone diseases, creates clean environment, promotes good nutrition and nutritional supplements through direct aid program. Poor health in children reduces time in school resulting to low levels of achievement. Similarly, Lopez (2006) argues that, illness of pre-school age children have permanent negative effects on children's experience when they are of school age.

Neil (2007) contends that the Lang'ata Health Center and the MSF Belgium Clinic in Kenya were identified for the purpose of collaborating with CARE in provision of medical services to children in ECD centers. In response to this a total of 1084 children from the centers received a variety of health services, including immunization, deworming, growth monitoring, vitamin supplements and treatment of minor illnesses like respiratory infections and ringworm. In addition, ECD center staffs were trained on record keeping, treatment of children and maintenances of immunization records to track absenteeism due to illness to protect children's education. Healthy children actively explore their environment to supplement on the knowledge gotten from teachers and parent to protect their education.

United States Agency International Development paralegal (USAID, 2012) in Migori County control mosquito bites by spraying liquid chemicals on walls of houses to kill female anopheles mosquito and by distributing treated mosquito nets to every household according to family size to protect children and their families from malaria. Besides, traditional birth attendants use herbs, special powder from pounded leaves and depark oil to treat diarrhea, anemia, respiratory infections and malaria as well as charcoal powder in treatment of wounds in children (Adawo, 2015). Medical services keep children in good health condition allowing good attendance, high concentration span and quality education.

\subsection{Theoritical Frame Work}

The impact of service provision and learning revolves around various theories and models such as input process output model and classical liberal theory of equal opportunity in education. The theoretical framework of this study provided rationale and logical basis of paralegal medical services underpinned on classical liberal theory of equal opportunity in education. The theory was postulated by Horace Man (1796 - 1890) and revised by Kiveu and Mayio, (2009) in determining the effect of cost sharing policy in education. The theory asserts that each person is born with a given amount of capacity, which to a large extent is inherited and cannot be substantially changed. The theory further states that there is a wide spread belief that by removing barriers and making more places available in upper Secondary and higher education and by increasing length of attendance in the common school an ideal situation would be created to implement vision of equal opportunity, where everybody has access to the kind and amount of education that suits his inherited capacity. 
Based on the premise of classical liberal theory (2009), removing barriers and increasing length of attendance in the common school for vision of equal opportunity to be implemented, there is a basic justification for provision of paralegal medical services. This ultimately will improve children's health condition which in-turn will increase length of class attendance providing enough opportunity for their education. Therefore, children need quality medical services for holistic development, as they are the future of the nation. Classical Liberal theory is used as a frame work for understanding children's medical requirement which is seen as an interactive and interrelated system. For instance, a traditional birth attendant provides medical services to children resulting to good health. Healthy children participate more in class activities hence low drop out, quality education and high productivity. The medical services provided should be adequately and consistently provided to treat diseases, prevent diseases, vaccinations and immunization to ensure good health condition. All paralegal medical services are of equal importance and synergistically interrelated. Provision of paralegal medical service is key to children's education whereby its provision removes barriers such as diseases in order to promote education while lack of it undermines children's right to education. Based on this theoretical underpinning the linkage between paralegal medical services and children's education has been conceptualized as indicated in figure 1.

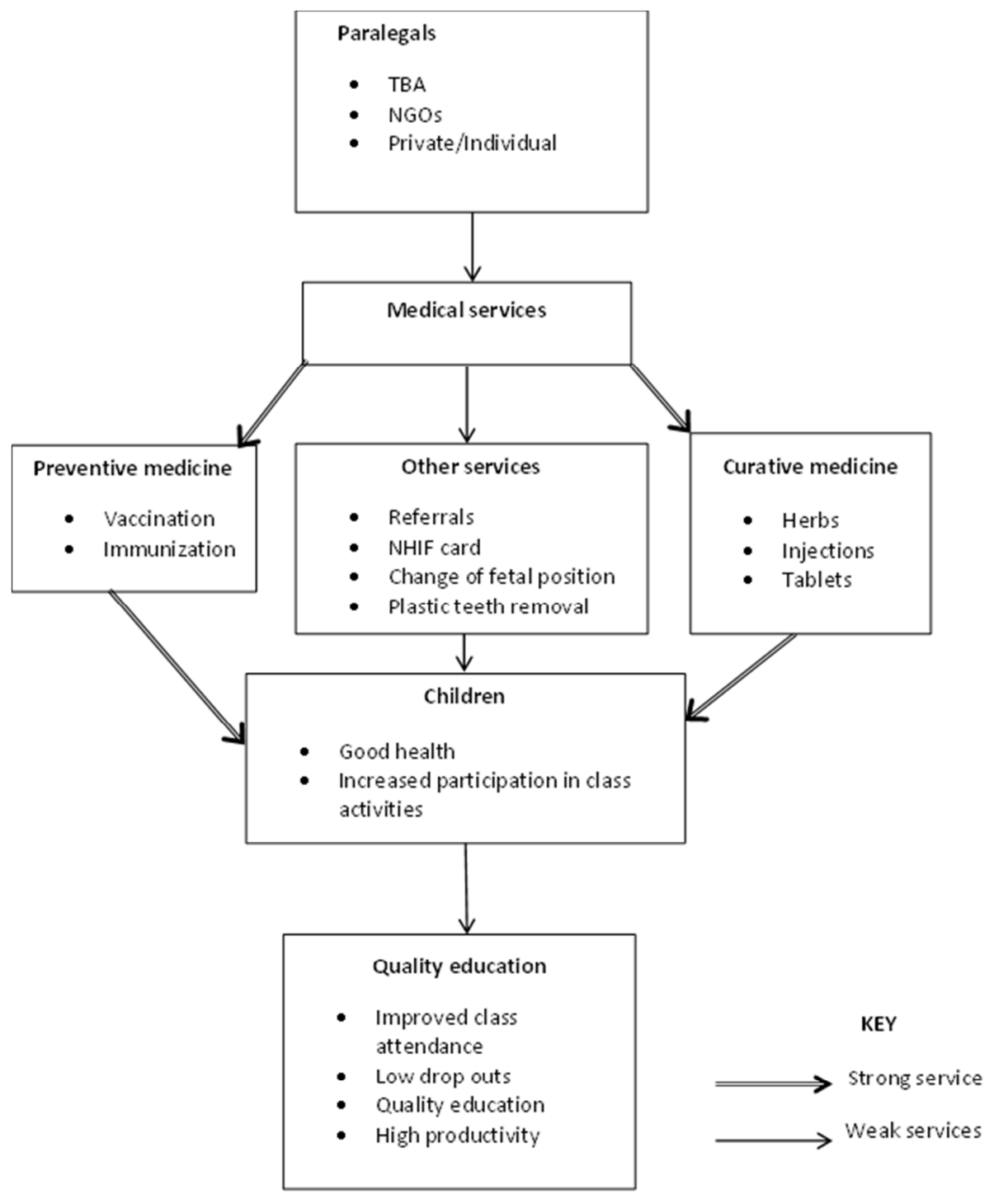

Figure 1. Conceptual Framework.

\section{Methodology}

The study adopted a survey research design in which descriptive method was used. Descriptive survey design is a way of collecting information by interviewing or administering a questionnaire to a sample of individuals and can be used when collecting information about people's opinion, attitudes, habits or any of the variety of education or social issues (Orodho and Kombo, 2002). The choice of descriptive survey research design was made based on the fact that the study was interested on the state of affairs already existing in the field. Descriptive survey design was 
therefore appropriate as it enabled the study to gather information concerning paralegal medical services and children's right to education. The design used two main approaches for data collection, processing and analysis viz. quantitative and analysis. Quantitative approach involving use of statistical package for social sciences was applied to run descriptive analysis to generate frequency distribution and percentages while charts and tables were produced using MS-Excel. Qualitative analysis considered inferences made from views and opinions of respondents.

A combination of simple random sampling and purposive sampling procedure was applied to identify NGOs and individual paralegals that met specific criteria. This, with the exception of traditional birth attendants who were sampled due to their limited number and the role they played in ensuring child survival besides providing medical services to children. The study required informed specialists as Luck and Reuben (1992) puts it, so health officers and children officers were purposively selected. Head teachers, teachers and parents were also purposively selected, as they were most appropriate to inform the study of paralegal medical issues. However, simple random sampling technique and purposive sampling procedure was applied to pick children from specific cohort of ECE centers. These respondents had equal chances of selection into intended samples (Mugenda and Mugenda, 1999). The entire sampling matrix yielded a total sample size of 348 respondents for the study.

Data for achieving objectives of the study was obtained from secondary and primary sources. Primary data was sourced through self- administered questionnaires and interview schedules from sampled population while secondary data sources included official documents, review reports and internet profound which was used as a supplement to primary sources.

Questionnaire and interview schedules were the instruments used to collect data from the respondents. Questionnaires were divided into two parts to capture both demographic information of respondents and issues raised from stated objectives contained both structured and unstructured questions. The questions targeted NGOs, individual paralegals, head teachers, ECE teachers, health officers and children's officer. The researcher personally distributed the questionnaires to the respondents and collected them back after 2 days to avoid misplacements and losses which could arise due to time span. Interview schedules targeting parents, traditional birth attendants and children were developed in search a manner that, the questions revolved around the objective. The researcher visited respondents for interviewing purposes which was done face to face to avoid malice. Both quantitative and qualitative techniques were applied to process, analyze and interpret data. Quantitative data was summarized, organized and arranged into themes and then averages, frequencies and percentages were calculated (Orodho, 2005). After data collection, cross examination was done to ascertain accuracy, sorted, edited and coded, keyed into the computer for analysis quantitatively using statistical data for social sciences (SPSS). Scores of respondents in each item were recorded to give overall score and then converted to percentages expressed as percentage of overall score. Qualitative data was organized and arranged in line with key thematic areas, summarized and presented in narrative form where possible, tabular forms indicating frequencies, averages and percentages. Systematic analysis and interpretation of the preliminary report was done and integrated with qualitative data in the final report (Best and Khan, 2004).

\section{Findings}

Presented in this section are study findings based on demographic characteristics of respondents and influence of paralegal medical services on children's right to education.

\subsection{Respondents Disaggregated by ED. and Professional Qualification}

The study sought to find out educational qualifications of the respondents as well as work experience. Academic qualifications and professional orientation are great indicators of one's potential towards problems solving and productivity.

Table 1. Distribution of respondents by educational qualification.

\begin{tabular}{|c|c|c|c|c|c|c|c|c|c|c|c|c|c|c|c|c|}
\hline \multirow[t]{2}{*}{$\begin{array}{l}\text { Educational } \\
\text { qualification }\end{array}$} & \multicolumn{2}{|c|}{$\begin{array}{l}\text { Individual } \\
\text { Paralegal } \\
\end{array}$} & \multicolumn{2}{|c|}{$\begin{array}{l}\text { Traditional } \\
\text { birth attendants }\end{array}$} & \multicolumn{2}{|c|}{$\begin{array}{l}\text { Child } \\
\text { officer }\end{array}$} & \multicolumn{2}{|c|}{$\begin{array}{l}\text { Health } \\
\text { officers }\end{array}$} & \multicolumn{2}{|c|}{ NGO } & \multicolumn{2}{|c|}{$\begin{array}{l}\text { Head } \\
\text { teachers }\end{array}$} & \multicolumn{2}{|c|}{$\begin{array}{l}\text { ECE } \\
\text { teachers }\end{array}$} & \multicolumn{2}{|c|}{ Parents } \\
\hline & $\mathrm{F}$ & $\%$ & $\mathrm{~F}$ & $\%$ & $\mathrm{~F}$ & $\%$ & $\mathrm{~F}$ & $\%$ & $\mathrm{~F}$ & $\%$ & $\mathrm{~F}$ & $\%$ & $\mathrm{~F}$ & $\%$ & $\mathrm{~F}$ & $\%$ \\
\hline None & 0 & 0 & 15 & 83 & 0 & 0 & 0 & 0 & 0 & 0 & 0 & 0 & 0 & 0 & 12 & 30 \\
\hline KCPE / CPE & 0 & 0 & 3 & 17 & 0 & 0 & 0 & 0 & 0 & 0 & 0 & 0 & 2 & 11 & 8 & 20 \\
\hline O level & 11 & 69 & 0 & 0 & 0 & 0 & 0 & 0 & 0 & 0 & 0 & 0 & 0 & 0 & 8 & 20 \\
\hline A level & 0 & 0 & 0 & 0 & 0 & 0 & 0 & 0 & 0 & 0 & 0 & 0 & 0 & 0 & 0 & 0 \\
\hline Certificate & 4 & 25 & 0 & 0 & 0 & 0 & 4 & 22 & 4 & 27 & 14 & 70 & 12 & 63 & 6 & 15 \\
\hline Diploma & 1 & 6 & 0 & 0 & 0 & 0 & 11 & 61 & 9 & 60 & 4 & 20 & 5 & 26 & 4 & 10 \\
\hline University & 0 & 0 & 0 & 0 & 11 & 0 & 3 & 17 & 2 & 13 & 2 & 10 & 0 & 0 & 2 & 5 \\
\hline Totals & 16 & 100 & 18 & 100 & 1 & 100 & 18 & 100 & 15 & 100 & 20 & 100 & 19 & 100 & 40 & 100 \\
\hline
\end{tabular}

Naudeau (2011) noted there is a strong correlation between staff qualifications and ECE outcomes.

This is based on the realization that roles defined on professional orientation and academic achievement contributes towards increased efficiency towards the set goals. The responses obtained were tabulated in table 1 . The results indicated that $1(100 \%)$ child officer, $3(17 \%)$ health officers, 2 (13\%) NGO personnel, 2 (10\%) head teachers and 
$2(5 \%)$ parents were graduates. Also (6\%) individual paralegals, $11(61 \%)$ health officers, $9(60 \%) \quad \mathrm{NGO}$ personnel, $4(20 \%)$ head teachers, $5(26 \%)$ ECE teachers and $4(10 \%)$ parents were diploma holders in various fields. However, the study revealed that $4(63 \%)$ individual paralegal, $4(22 \%)$ health officer, 4 (27\%) NGO personnel, $14(70 \%)$ head teachers, $12(63 \%)$ ECE. T and $6(15 \%)$ parents were certificate holders. More striking point thought was that, $11(69 \%)$ individual paralegal; and $8(20 \%)$ parents, $2(11 \%)$ ECE. T and $3(17 \%)$ TBAs were O' level holders and below. Worse still $15(83 \%)$ TBAs were not learned at all. The results indicated that out of $147(100 \%)$ respondents $88(60 \%)$ were professionals in various fields. Gumo (2003) noted that specialists with high educational level are known to possess appropriate knowledge, skills, values and attitudes indicating that they are competent in implementing best practices thus influencing what learners achieve through providing quality health services.

For work experience $36(24.5 \%)$ respondents had 1-9 years, $43(29.3 \%)$ had $10-19$ years, $47(31.9 \%)$ had $20-29$ years whereas only $21(14.3 \%)$ had experience for over 30 years in paralegal health services. Majority of respondents 43 $(29.3 \%)$ and 47 (31.9\%) had an experience of 10-19 and 2029 respectively. Similarly, TBAs had wide exposure to paralegal health services with 17 (94\%) having worked for 20 years and above while only $1(6 \%)$ had less than 19 years. This signified that the paralegals were capable of providing adequate health services through use of appropriate approaches during counseling and awareness creation as well as maintenance of proper professional documents.

\subsection{Population in the ECE Centre by Category}

A category of children in the ECE centers signifies improvement in provision of ECE services. If children are well protected through provision of quality health services the categories of children enrolled in ECE centers increases significantly. The study therefore sought to find out the total population in the ECE centers used for the study by category.

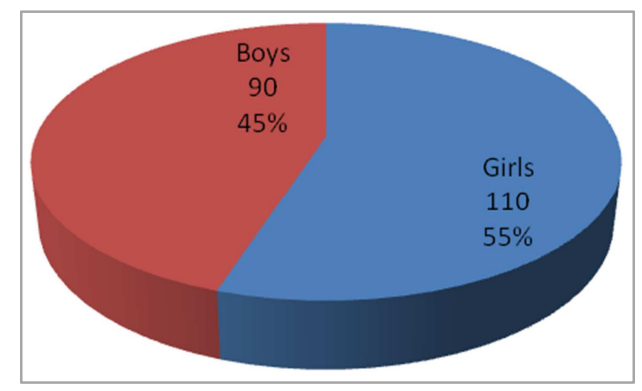

Figure 1. Gender of the ECE Children.

The study findings were tabulated as shown figure 2 . According to the study findings $110(55 \%)$ of the ECE children interviewed were girls while $90(45 \%)$ were boys. The study further sought to find the number of ECE children by category. About 78 (39) of the children interviewed were orphans and vulnerable, $56(28 \%)$ were sick and malnourished, while the rest $66(33 \%)$ were found to be suffering no disease. In all categories the total number of girls was found to be slightly higher than that of boys.

Based on the study findings, there was a positive indication that all categories of children were found in the ECE centers. It was not in doubt that the paralegal provision of medical services was not sufficient enough to protect children's right to Education. More still, enrolment of more orphans and vulnerable children as opposed to any other category was an indicator that though inadequate the paralegal medical services were provided.

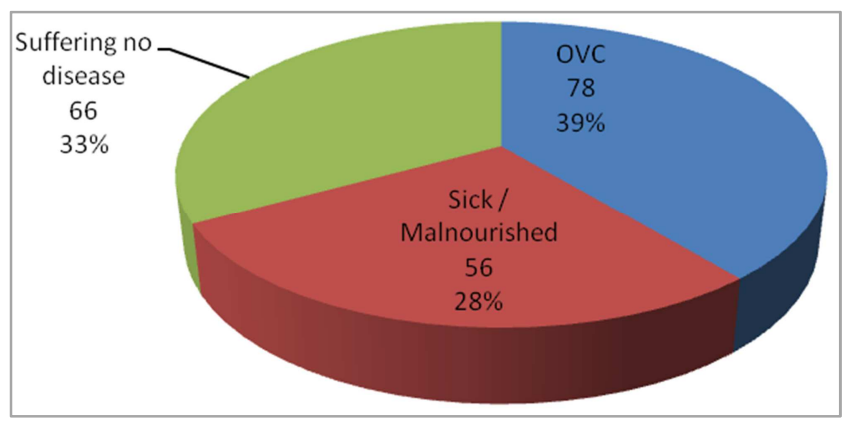

Figure 2. Categories of children in ECE centers.

Studies carried out by Hamadan and Huda (2006) revealed that AHA delivers holistic care to those who need it and make lasting improvements to devastated health care systems.

\subsection{Effect of Paralegal Medical Services on Children's Education}

Adequate medical services improve children's health condition making them active and strong enough to adjust to unfavorable conditions in the environment hence protecting their rights to Education. In cases where there are insufficient medical services children's health deteriorates and they cannot fully participate in ECE activities. To determine this, the study sought to examine extent to which paralegals provide medical services to ECE children as shown in figure 4.

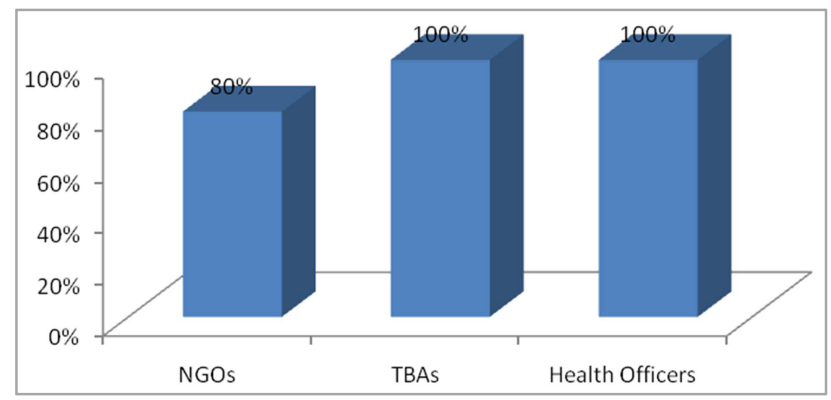

Figure 4. Medical Service Providers to ECE Children.

The study analysis indicated that $12(80 \%)$ out of 15 $(100 \%)$ NGOs, $18(100 \%)$ TBAs and $18(100 \%)$ health officers offered medical services to children. Richter and foster (2006) in agreement with this affirm that AHA provides basic preventative and curative services with a focus on most vulnerable children. However, the entire individual paralegals and children's officer do not directly offer medical 
services but instead refer the children to government medical facilities. This argument was based on the fact that they were not legally authorized to provide medical services.

The results pointed out a dire need to equip individual paralegals with medical knowledge to enhance their skills in medical provision in order to protect children's right to Education. Findings were in conformity with Neil's (2007) findings that communities should be provided with a broad spectrum of medical support and care services, along with information, education and communication services including diagnosis, treatment and prevention.

\subsubsection{Treatment of ECE Children}

The study intended to find out whether the children were receiving medical services from the paralegals or not. It was important to seek the opinion of ECE children. ECE children were first asked if they ever fell sick and the results shown as in figure 5.

The result showed that 196 (98\%) had fallen sick while 4 (2\%) had not. An indication that the paralegals needed to offer more quality health services to protect children's education.

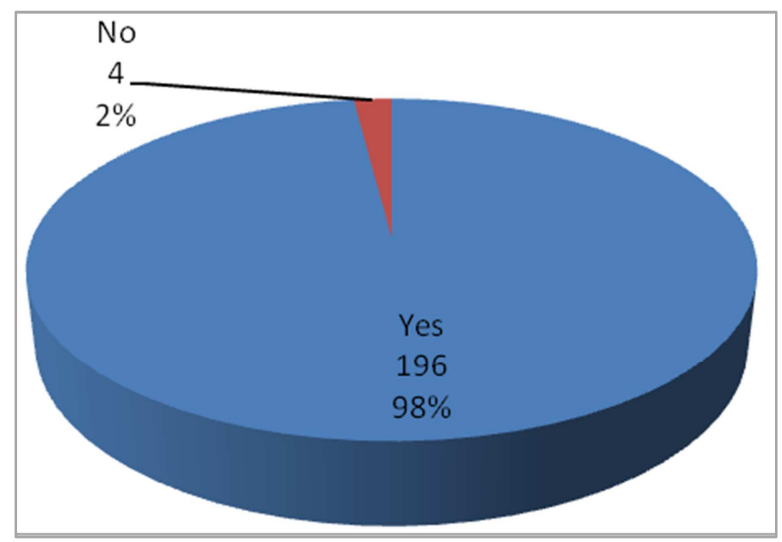

Figure 3. Sick children.

The study further sought to know where the ECE children were treated and the results indicated as shown in figure 5. The study findings revealed that $90(45 \%)$ children received treatment from hospitals, $48(24 \%)$ from TBAs and $62(31 \%)$ from home. About $56(28 \%)$ had received medical services from hospital, TBAs, home, or NGOs that offered such medical services.

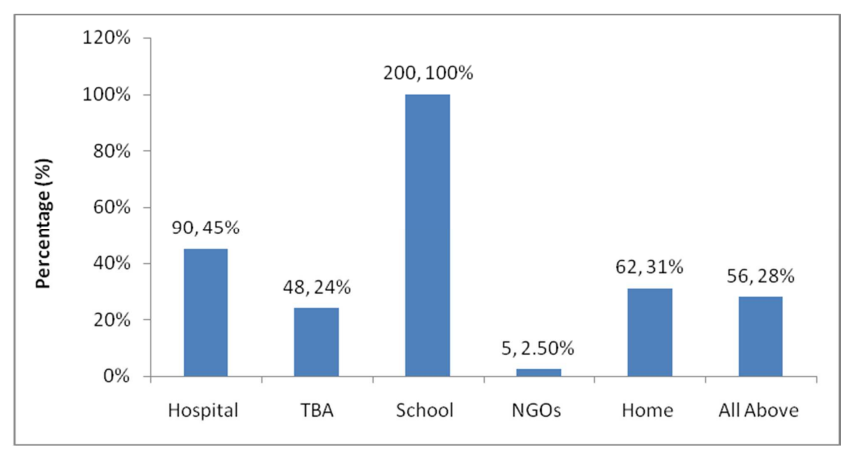

Figure 4. Place of treatment when sick.
All the $200(100 \%)$ children admitted getting treatment in school. The results in Figure 4 indicated there was no specific place of treatment for the ECE children. An individual child could be treated in hospital, home, school, by a TBA or an NGO depending on type of disease, time the child fell sick and whether there was cash at hand for treatment or not. In one rare instance, a child had this to say in the presence of the mother "when l am sick, my mother picks leaves, grinds them, then mixes them with water and gives me to drink". The voice of child captured confirmed that treatment of a child was sought anywhere depending on the state of emergency. When the study sought to know why treatment was offered by the mother and whether she was trained or not, the response given was "I am not trained but I seek advice from some herbalists which I use when in a fix". The statement concurred with Dunn's (2004) argument that, AHA paralegal train mid-wives and traditional attendants to reduce maternal and child mortality.

\subsubsection{Receipt of Medical Services to Protect Children's Education}

To confirm receipt of medical services by the children, it was imperative to carry out a similar investigation from ECE teachers, Head teachers and parents as indicated in figure 7.

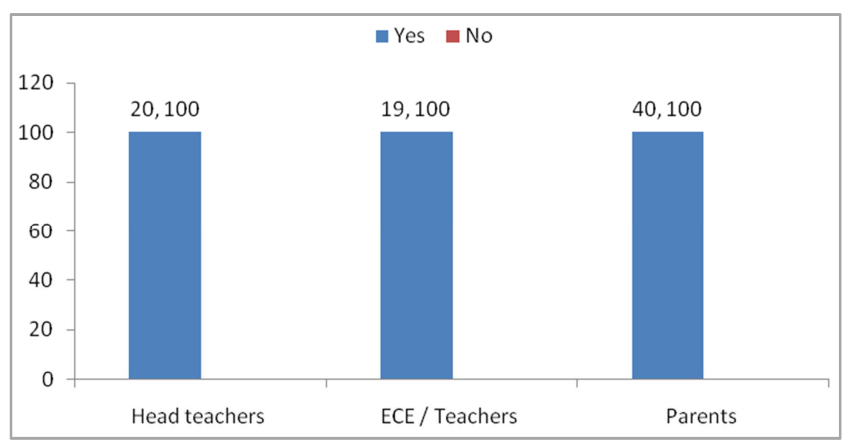

Figure 5. Receipt of medical services.

The study findings indicated that $79(100 \%)$ recipients admitted receiving medical services for their ECE children. Out of $20(100 \%)$ Head teachers, 17 (85\%) reported receiving medical services from NGOs and $3(15 \%)$ others from health officers, $19(100 \%)$ ECE teachers received medical services from NGOs and 2 (10.5\%) from hospitals. Further analysis indicates that $28(70 \%)$ parents purport that their children received medical services from TBAs, 26 $(65 \%)$ from health officers and $4(10 \%)$ from NGOs. More still, only $2(5 \%)$ parents admitted receiving medical services from individual paralegals.

Study analysis indicates that most recipients received medical services from NGOs and health officers while the TBAs and individual paralegal services were received by parents only.

CARE (2005) in a separate study revealed that for young children's health to improve communities need access to quality health clinics, safe water and sanitation. Good health provide enough time for children's education. 


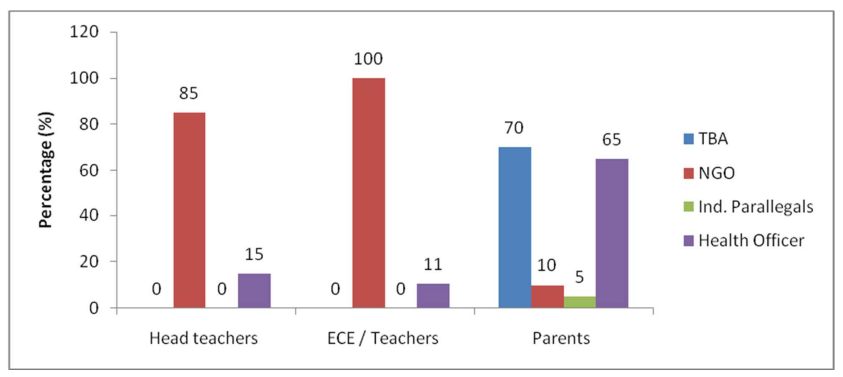

Figure 6. Sources of medical services by the recipients for the ECE children.

\subsubsection{Types of Medical Services Offered by the Paralegals}

The study intended to find out the type of medical services offered by the paralegals. It was important as the type of medical services offered by the paralegals determine the contribution made by each in improving children's health to protect their rights to Education. The information realized is presented as in table 2 . The study analysis indicated that 12 $(75 \%)$ out of $16(100 \%)$ individual paralegal, $6(40 \%)$ out of $15(100 \%)$ NGOs and $1(5.5 \%)$ out $18(100 \%)$ TBAs make referrals to health facilities as a means of aiding in ensuring that children get medical services. This study was in conformity with that done by Richter and Adato (2009) which stated that the paralegals also provide referral services and follow up treatment.

Table 2. Types of medical services offered by the paralegals.

\begin{tabular}{|c|c|c|c|c|c|c|}
\hline & $\begin{array}{l}\text { Individual } \\
\text { paralegals }\end{array}$ & & NGO & & TBA & \\
\hline Medical services & $\mathrm{F}$ & $\%$ & $\mathrm{~F}$ & $\%$ & $\mathrm{~F}$ & $\%$ \\
\hline Make referrals & 12 & 75 & 6 & 40 & 1 & 6 \\
\hline Deworming & 1 & 6 & 3 & 20 & 1 & 6 \\
\hline CT & 2 & 13 & 0 & 0 & 0 & 0 \\
\hline $\begin{array}{l}\text { Vaccination BCG\& } \\
\text { Polio }\end{array}$ & 1 & 6 & 4 & 27 & 0 & 0 \\
\hline Injections & 0 & 0 & 0 & 0 & 0 & 0 \\
\hline Syrups and tablets & 0 & 0 & 0 & 0 & 0 & 0 \\
\hline $\begin{array}{l}\text { Referrals and } \\
\text { vaccination }\end{array}$ & 0 & 0 & 2 & 13 & 0 & 0 \\
\hline $\begin{array}{l}\text { Changing baby } \\
\text { position in womb }\end{array}$ & 0 & 0 & 0 & 0 & 4 & 22 \\
\hline Provision of ointment & 0 & 0 & 0 & 0 & 1 & 5 \\
\hline $\begin{array}{l}\text { Herbs to expectant } \\
\text { mothers }\end{array}$ & 0 & 0 & 0 & 0 & 9 & 50 \\
\hline $\begin{array}{l}\text { Removal of plastic } \\
\text { teeth }\end{array}$ & 0 & 0 & 0 & 0 & 2 & 11 \\
\hline Total & 16 & 100 & 15 & 100 & 18 & 100 \\
\hline
\end{tabular}

Further analysis indicated that $1(6 \%)$ out of $16(100 \%)$ individual paralegal, $3(20 \%)$ out of $15(100 \%)$ NGOs and 1 (5.5\%) out of $18(100 \%)$ TBAs offered deworming medicine while $1(6 \%)$ out of $16(100 \%)$ individual paralegal, $6(40 \%)$ out of $15(100 \%)$ NGOs and $1(5.5 \%)$ out of $18(100 \%)$ TBAs provided vaccination services against polio and BCG. Likoye and Ongwenyi (2006) in a separate study indicated that by using ECD centers as vaccination sites and building relationships with regular clinics that provide regular immunization rates of vaccination can be considerably improved. More still, the major medical service offered by the TBAs are geared towards smooth development of the unborn child, where giving herbal medicine to the expectant mother represent $9(50 \%)$ out of $18(100 \%)$ and changing fetal position in the womb represents $4(22.2 \%)$ out of 18 (100\%) of their medical services. Moreover, 2 (11.1\%) TBAs out of $18(100 \%)$ removed plastic teeth for newborn babies.

The results from paralegals provision of medical services indicated that each of the individual paralegal, NGOs and TBAs play a great role in ensuring survival of the child. Although the government through public hospitals is the major provider of medical services to ECE level children, sometimes the services are out of reach prompting the recipients to seek help from the paralegal within reach. This makes paralegal medical services a cornerstone of ECE regardless of whether they are unqualified and acting as private institution or a combination.

\subsubsection{Category of Children Who Received Medical Services from the Paralegals}

Adequate provision of medical services to each category ensured all children are in good health condition to spend maximum time in school. The study therefore sought to find out the target of each paralegal by category. Study findings indicated that individual paralegals and NGOs mainly focus on OVC. $9(56 \%)$ out of $16(100 \%)$ individual paralegals, 8 $(53 \%)$ out of $15(100 \%)$ NGOs have interest on OVC. Further analysis show that health officers, head teachers, ECE teachers and TBAs received and offered medical services to all children.

Table 1. Category of children receiving medical services.

\begin{tabular}{lllllll}
\hline $\begin{array}{l}\text { Categories of } \\
\text { Children targeted }\end{array}$ & $\begin{array}{l}\text { Individual } \\
\text { Paralegal }\end{array}$ & & TBA & \multicolumn{3}{c}{ NGOs } \\
\hline & F & $\%$ & F & $\%$ & F & $\%$ \\
OVC & 9 & 56 & 0 & 0 & 8 & 53 \\
Malnourished & 9 & 56 & 4 & 22 & 3 & 19 \\
All sick & 0 & 0 & 0 & 0 & 0 & 0 \\
\hline
\end{tabular}

The result revealed that all categories of children receive medical services either directly from health officers and traditional birth attendants or indirectly from individual paralegals and NGOs through Head teachers and ECE teachers. However, across visit by CARE (2006) staff between country offices presented a contrasting statement that in sub-Saharan countries the entire age group between 0 8 was not accessing treatment and care services hindering children's education.

\subsubsection{Frequency of Paralegal Services Offered to Protect Children Rights to ECE}

The study sought to determine how often the paralegals offered medical services to protect children's right to ECE. The findings realized are shown in table 4. The study findings indicated that out of $18(100 \%)$ TBAs 12 (66.7\%) often provided medical services while $6(33.3 \%)$ sometimes provided medical services to the ECE children due to condition of the child that they could not comprehend. 
Table 4. Frequency of paralegal medical services to protect ECE Children.

\begin{tabular}{lllllll}
\hline & TBA & & NGO & \multicolumn{3}{c}{$\begin{array}{l}\text { Individual } \\
\text { Paralegal }\end{array}$} \\
\hline Often & F & $\%$ & F & $\%$ & F & $\%$ \\
Sometimes & 12 & 67 & 6 & 40 & 9 & 56 \\
Never & 6 & 33 & 7 & 47 & 6 & 38 \\
Total & 0 & 0 & 2 & 13 & 1 & 6 \\
\hline
\end{tabular}

Out of $15(100 \%)$ NGOs $6(40 \%)$ often offered medicals services, 7 (46.7\%) sometimes while $2(13.3 \%)$ never offered medical services since it was not in their professional docket. Out of $16(100 \%)$ individual paralegal. 9 (56.3\%) often, 6 $(37.5 \%)$ sometimes and $1(6.2 \%)$ never provided medical services since she was not a trained paralegal. It was evident from the study findings that majority of the paralegals often provided medical services to protect children's right to education. In agreement with this, CARE (2006) uses childcare settings as initial point of intervention within a community provide an effective focal point around which services benefiting caregivers households and individual children can be organized and delivered to ensure children learn well.

\subsubsection{Effectiveness of Medical Services Offered by the Paralegals}

The study sought to examine effectiveness of medical services offered by the paralegals. Effectiveness of medical services is of critical concern to the government and so to all paralegals and recipients. This is based on the argument that when medical services are ineffective, poor health and poor use of study time among the learners results.

Confirming these arguments are paralegal and recipients affirmative response and discussions of effects as in Table 5.

Table 5. Effectiveness of Medical Services Offered by the Paralegals.

\begin{tabular}{|c|c|c|c|c|c|c|c|c|c|c|c|c|}
\hline \multirow[t]{2}{*}{ Responses } & \multicolumn{2}{|c|}{ Individual Paralegal } & \multicolumn{2}{|c|}{ NGO } & \multicolumn{2}{|c|}{ PARENTS } & \multicolumn{2}{|c|}{ TBA } & \multicolumn{2}{|c|}{ ECE. T } & \multicolumn{2}{|c|}{ Head Teachers } \\
\hline & $\mathrm{F}$ & $\%$ & $\mathrm{~F}$ & $\%$ & $\mathrm{~F}$ & $\%$ & $\mathrm{~F}$ & $\%$ & $\mathrm{~F}$ & $\%$ & $\mathrm{~F}$ & $\%$ \\
\hline Effective & 16 & 100 & 15 & 100 & 40 & 100 & 18 & 100 & 19 & 100 & 20 & 100 \\
\hline Ineffective & 0 & 0 & 0 & 0 & 0 & 0 & 0 & 0 & 0 & 0 & 0 & 0 \\
\hline Total & 16 & 100 & 15 & 100 & 40 & 100 & 18 & 100 & 19 & 100 & 20 & 100 \\
\hline
\end{tabular}

Analysis of the findings showed that 16 (100\%) individual paralegals indicated that medical services were effective. Similarly, all the medical service providers and recipients admitted to the services being effective. The findings of the paralegals and recipients concurred with that of Caspe and Lopez (2006) that CHEWs train caregivers on the most effective methods of providing care and treatment, monitor hygiene and nutrition of all household members.

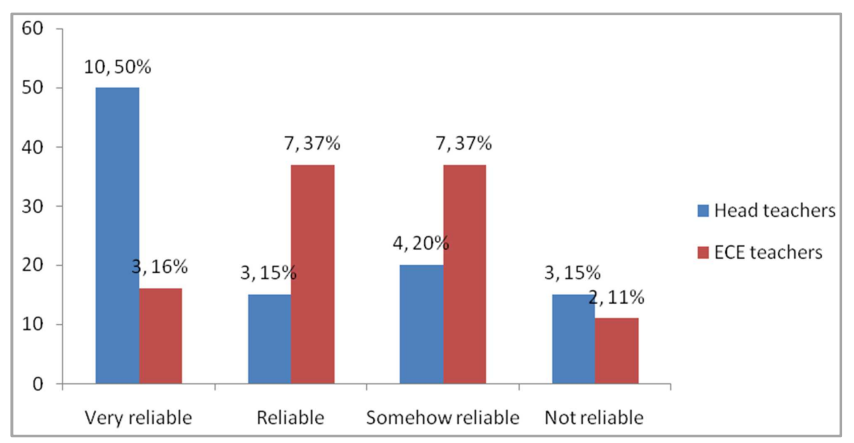

Figure 9. Reliability of medical services.

\subsubsection{Reliability of the Inflow of Medical Services}

The study sought to determine reliability of the inflow of medical services on protection of children's right to Education. Most paralegals often rely on their head offices which could be situated far away from them for supply of resources. In instance where the resources are readily released from their head offices the inflow of medical services are reliable. However, in cases where resources are not available, laxity and poor communication incorporated, the inflow of medical services are unreliable and children's health deteriorate resulting to poor school attendance. To determine this, head teachers and ECE teachers were asked how reliable the inflow of medical services was and the findings summarized in figure 9.

Study findings indicated that out of $20(100 \%)$ head teachers, $17(85 \%)$ admitted that they received awareness/sensitization services, out of 19 (100\%) ECE teachers $15(78.9 \%)$ and out of $40(100 \%)$ parents $32(80 \%)$ received the services.

Study findings indicated that out of $20(100 \%)$ head teachers, $17(85 \%)$ admitted that they received awareness/sensitization services out of 19 (100\%) ECE teachers $15(78.9 \%)$ and out of $40(100 \%)$ parents $32(80 \%)$ received the services. The ECE children in good health condition could be noticed right from the entrance into the institution, very active from outdoor activities to the indoor activities hence full participation resulting to good performance. To ensure reliability of medical services IAPThika provides training for all CHWs to enhance their ability to support the physical and psychological health of PLHA (Victoria, 2009).

\subsubsection{Challenges Paralegals Face in Provision of Medical Services to Children}

The study sought to identify challenges faced by the paralegals in provision of medical services to ECE children in the county.

The challenges put forward by the paralegals were summarized as indicated in table 6

The bulk of paralegals $15(22 \%)$ out of $68(100 \%)$ mentioned poverty and lack of funds as the major hindrance to provision of medical services. This was closely followed by $9(13.2 \%)$ of the paralegals who reported cultural and religious believes among the parents. Another 14 (21\%) paralegals felt that the medicine was inadequate and the care 
givers had limited skills. Further still, $6(8.8 \%)$ indicated failure to pay for services offered while $5(7.4 \%)$ felt lack of gloves hampered their service provision. Moreover, Still 3 (4.4\%) expressed that ignorance, poor infrastructure and cleared bushes hindered their provision of services. Worse Still $2(2.9 \%)$ reported risky night operations attributed emergencies during the night.

Table 6. Challenges faced by the paralegals in provision of medical service to Children.

\begin{tabular}{ll|llllll}
\hline \multirow{2}{*}{ Responses } & \multicolumn{2}{l}{ Individual P } & \multicolumn{2}{l}{ NGOs } & \multicolumn{2}{l}{ TBAs } \\
\cline { 2 - 7 } & F & \% & F & $\%$ & F & $\%$ \\
\hline lack of funds & 10 & 63 & 2 & 13 & 2 & 11 \\
Cultural / religious believes & 1 & 6 & 3 & 20 & 0 & 0 \\
Lack of follow ups & 1 & 6 & 0 & 0 & 0 & 0 \\
Limited skills from care givers & 3 & 19 & 4 & 27 & 0 & 0 \\
Slow laboratory & 1 & 6 & 0 & 0 & 0 & 0 \\
Ignorance & 0 & 0 & 3 & 20 & 0 & 0 \\
Poor infrastructure & 0 & 0 & 3 & 20 & 0 & 0 \\
Cleared bushes & 0 & 0 & 0 & 0 & 3 & 17 \\
Lack of gloves & 0 & 0 & 0 & 0 & 5 & 28 \\
Failure to pay for services & 0 & 0 & 0 & 0 & 6 & 33 \\
offered & 0 & 0 & 0 & 0 & 2 & 11 \\
Risky night operations & 16 & 100 & 15 & 100 & 18 & 100 \\
\hline Total & & & & &
\end{tabular}

The least reported among the paralegal challenges were incidence of lack of follow-ups and slow laboratory tests. Besides the paralegal challenges, there were also issues facing recipients of paralegal medical services. The head teacher's responses are not discussed, since they got result of medical services from ECE teachers. Out of $59(100 \%)$ the largest number of recipients $26(44 \%)$ cited side effects of drugs like vomiting and body weaknesses as challenges faced by ECE children after intake of drugs offered by the paralegals. This was closely followed by $12(20.3 \%)$ of the recipients who reported slow laboratory tests and $8(13.5 \%)$ who faced inadequate provision of medicine $6(10 \%)$ were faced with issues of limited skills from care givers and 5 $(8.5 \%)$ negative attitudes of parents while the least cited was cultural and religious believes.

It is evident from Table 6, that some of the issues stated by the paralegals were similar to sentiments of recipients. This included cultural and religious believes, inadequate provision of medicine, limited skills from care givers, slow laboratory tests, negative attitudes of parents and side effect of drugs. In addition the children officer reported lots of cultural and religious interference from the care takers regarding his responsibilities. The challenges put forward hindered provision of medical services to ECE children as the paralegals were unable to offer quality services in terms of adequate medicine human resources and funds. IAP- Thika offers a number of services to PIHA and OVC including healthcare psychosocial support, legal advice, education, support for OVC, economic support, nutritional assistance and material items (Caspe, 2006).

\subsubsection{Measures Responding to Challenges in Medical Provision}

Suggestions were sought from the paralegals on possible ways to address medical provision.

Table 7. Measures to challenges in provision of medical services.

\begin{tabular}{lllllll}
\hline & \multicolumn{2}{l}{ Individual P } & \multicolumn{2}{l}{ NGO } & \multicolumn{2}{l}{ TBA } \\
\hline Measures & F & \% & F & \% & F & $\%$ \\
\hline Group contributions & 0 & 0 & 0 & 0 & 6 & 33 \\
Donor support & 2 & 12 & 15 & 100 & 0 & 0 \\
Income generating activities & 16 & 100 & 2 & 13 & 5 & 28 \\
Access to NHIF & 16 & 100 & 8 & 53 & 0 & 0 \\
Training and incentives & 0 & 0 & 0 & 0 & 0 & 0 \\
Follow ups and home visits & 16 & 100 & 2 & 13 & 1 & 6 \\
Training care givers & 2 & 13 & 5 & 33 & 0 & 0 \\
Sensitization / awareness & 1 & 6 & 3 & 20 & 0 & 0 \\
creation & 0 & 0 & 6 & 40 & 0 & 0 \\
Linkages and networking & 0 & 0 & 0 & 0 & 4 & 22 \\
Purchase & 0 & 0 & 0 & 0 & 2 & 11 \\
Referrals & & & & & & \\
\hline
\end{tabular}

The suggestions put forward by the respondents were summarized as indicated in table 7 .

The study findings revealed that out of $18(100 \%)$ TBAs 6 relied on group contribution and neither the NGOs nor the individual paralegals contributed in groups to solve their changes. While only $2(12 \%)$ TBAs and no individual paralegal depended on donor support all the NGOs 15 (100\%) majorly depended on donor support. The individual paralegals $16(100 \%)$ depended on income generating activities and only $2(13 \%)$ and $5(28 \%)$ NGOs and TBAs respectively depended on income generating activities.

Further still the individual paralegals 16 (100\%) wholly depended on access to NHIF and follow ups and home visits while only $2(13 \%)$ relied on training caregivers. However the entire individual paralegals never relied on training and incentives. More still, 8 (53\%) NGOs and $2(13 \%)$ and 5 (33\%) relied on access to NHIF, follow ups, home visits and training caregivers respectively. Only $1(6 \%)$ TBA relied on follow ups and home visits. Worse still, 1 (6\%) individual paralegal relied on sensitization/awareness, $3(20 \%)$ and 6 (40\%) NGOs relied on sensitization/awareness creation and only $4(22 \%)$ and $2(11 \%)$ TBAs depended on referrals as a solution to their problems. A separate study by Richter (2009) concurred with this view that IAP- Thika conducts meetings with up 30 guidance of OVC to provide opportunity for them to discuss the challenges they face.

\section{Summary, Conclusions and Implication}

The purpose of this study was to determine the influence of paralegal medical services on protection of children's right to education. To achieve this, primary data was sourced from the paralegals (traditional birth attendants, NGOs and individual paralegals), two outer players (health officers and children officers) and the recipients (children, parents, Headteacher and teachers) resulting to a total of 348 respondents. Quantitative data was summarized, organized 
according to research questions, arranged into themes and then averages, frequencies and percentages were calculated. Crossexamination was done, and then data was sorted, edited and coded, keyed in for analysis using SPSS. Qualitative data was summarized, organized and arranged into themes and presented in narrative form where it was possible, tabular forms indicating averages, frequencies, and percentages. The study found that children's education services were significantly related to paralegal medical services such as provision of drugs, herbs, immunization, vaccination, giving referrals and facilitation of NHIF cards. Children's education was also significantly related to paralegal demographic characteristics such as age, education and gender among others. The analysis indicated that out of the $49(100 \%)$ paralegals used in the study $15(30.6 \%)$ were not educated, 3 (6.1\%) were either KCPE/CPE certificate holders, 11 (22.4\%) O level, 8 (16.3\%) certificate holders, 10 (20.4\%) diploma and worse still, only $2(4.1 \%)$ were holders of bachelor degree certificate. The findings of study revealed that a greater percentage $29(59 \%)$ of the paralegals had no professional qualification but acquire knowledge on the job.

The study indicated a dire need for training of the paralegals in order to equip them with appropriate knowledge, skills, values and attitudes. This was to prevent further problems that could arise due to mishandling of patients with terminal diseases like HIV/AIDS and cancer which are common today. The study also indicated the paralegals had lots of experience thus diverse approaches to different health problem. This is in agreement with Neil's (2007) argument that communities should be provided with broad spectrum of medical support and care givers along with information, education and communication services including diagnosis, treatment and prevention. The findings indicate that the enrolment of OVC in ECE centers were more compared to other categories of children. In most cases, this category of children could not access medical services from the hospitals due to lack of finance, exposure and distance ending up in the hands of paralegals within reach. This underscores the significance of paralegal medical services in protection of ECE regardless of their qualification. Study findings confirmed that there was no specific place for treatment of children. An individual child could be treated anywhere by anybody depending on time, type of disease, level of exposure and financial position of the family. Thus, the Government through the county government needs to emphasize the training of paralegals to reduce child mortality and protect their education.

In Kenya a similar report from Dunn (2004) indicate that AHA paralegal train midwives and traditional birth attendants to reduce mental and child mortality. Critical examination of the type of medical services provided by each of the paralegal reveals that the TBAs were geared towards smooth development of the unborn child, changing fetal position and removal of plastic teeth for new born babies besides giving herbal medicine to expectant mothers and children to protect their education. The NGOs majorly makes referrals to health facilities, offers vaccinations and give tablets while the majority of individual paralegal made referrals and facilitated NHIF card access. The result indicate that each of the individual paralegal play a great role in ensuring child survival. In the absence of these, poor health condition interferes with children's full participation in educational activities. Although the study findings indicate that most paralegals were neither educated nor qualified, study analysis indicated that all the recipients admitted that services were effective. This is despite proper diagnosis of the disease and prescription of the dosage to be taken which was only imaginary. Thus, $100 \%$ acceptance of effectiveness of paralegal medical services reveals the position of the paralegals in the society. The County Government should incorporate the paralegals in provision of medical services to protect children's right to education. Study analysis reveal that the paralegals faced numerous challenges including but not limited to funds, risky night operations, lack of payment for services offered, limited skills from caregivers, cleared bushes, lack of gloves, cultural believes and ignorance among others. The county government needs to provide opportunity for the paralegals to discuss the challenges they face and look for solutions to protect children's education. A Similar study conducted by Richter, (2009) contend that IAP-Thika hold regular meetings with guidance of OVC. For paralegal medical services to positively impact on children's education there should be combined effort from a committed government, the paralegals and Caretakers.

\section{References}

[1] Action in Community Environment (2007). Child Rights and Welfare. Tanzania.

[2] Adawo, R. (2015). Influence of Paralegal Health Services on Protection of Children's Right to Education in Migori County, Kenya. Unpublished Med Thesis: UON.

[3] Best, J. W and Khan, J. V. (2004). Research in Education, 9 Edition. New Delhi: Prentice Hall of India Private Limited

[4] CARE, (2005). 5x5 Model. Lessons Learned Nkundabana; $A$ Model for Community Based Care for Orphans and Vulnerable Children. Rwanda.

[5] CARE, (2004). An Initiative Supporting the Basic Income Needs of HIV/AIDs Affected Households and Individuals. Kenya.

[6] Caspe, M \& Lopez, M. E. (2006). Lessons from Family Strengthening Interventions; Learning from Evidence Based Practices Cambridge. Mass Harvard Victoria.

[7] Cowley, J. I. (2010). A comparative Study of Para - legalism in Australia. US.

[8] EFA, (2007). Education for All, Global Monitoring Report: Strong Foundations, Early Childhood Care and Education. Paris, UNESCO.

[9] Gumo, A. W. N. (2003). Teacher Factors Related to Teaching of Art and Craft in Kaloloni and Kikambala District Unpublished Med Thesis: KU. 
[10] Hamadan, J. and Huda, S. (2006). Psychosocial Stimulation Improves the Development of Undernourished Children: The Journal of Nutrition. 136, 10.

[11] http://en.wikipedia.org/wiki/paralegal\#reference

[12] http://www.Unicef.org/southafrica/saf-resourcesecdguidlines.pdf

[13] Kiveu, N. M and Mayio, J. (2009). The Impact of Cost Sharing on Internal Efficiency of Public Secondary Schools in Ndivisi Division, Bungom District Kenya. Educational Research and Review 4 (5): 272-284.

[14] Likoye, F and Ongwenyi, Z. (2006). Evaluated Report of Integrated AIDS Programme (IAP) in Mangu China and Kenya: Women"s Education Research of Kenya (WERK) in Collaboration with IAP. Kenya.

[15] Luck, V. and Reuben, J. (1992). Methodology of education Research: New Delhi, Vani Education Book

[16] MC Michael, A. J (2000). The urban Environment and Health in a World of Increasing Globalization: Issues for Developing Countries. Bulletin of WHO.

[17] Mugenda, O. M. and Mugenda, A. G. (1999). Quantitative and qualitative Approach, University Press.

[18] Nossal, G. J. V. (2000). The Global Alliance for Vaccine and Immunization - A Millennial Challenge, Prometheus: Critical Studies in Innovation 18 (1): 33-37.

[19] Neil, E. (2007). Perception of Child Health in Kibera an Urban Slum in Nairobi: Emorri Rollins School of Public Health; Masters Thesis, UON.

[20] Onditi, L. (2014). Community Initiative for Paralegal Development Organization. Migori County. Kenya.

[21] Orodho, A. J. \& Kombo D. K. (2002). Research Methods Nairobi: Masola Publishers.

[22] Orodho, J. A. (2005). Techniques of Writing Research Proposals; Kenya. Masola Publishers.
[23] Raleigh, N. C. (2014). Advocate for Children Services Annual Report. North Carolina.

[24] Richter, L., Foster, G. and Sherr, L. (2006). Where the Heart Is: Meeting the Psychosocial Needs of Young Children in the Context of HIV/ AIDS. Benard Van Leer Foundation.

[25] Richter, L., Sherr, L. and Adato, M. (2009). Strengthening Families to Support Children Affected by HIV/AIDS: AIDS Care: Psychological and Social Medical Aspects of HIV/AIDS 21 (3-12) Rwanda.

[26] Renee, T. \& Nendorf, K. (2006). Pathfinder International Community Based HIV/AIDs Prevention, CARE and Support Programme: A Case Study of Integrated AIDS Programme, Kenya.

[27] Republic of Kenya, (2006). National Early Childhood Development Policy Framework, Nairobi: Government Printers.

[28] Warner, R. (2004). The Independent Paralegal Handbook: California.

[29] WHO, (2014). African Humanitarian Action Annual Report. Ethiopia.

[30] WHO and UNICEF (2005). Child and Adolescent Injury Prevention: A global Call to Action. Geneva.

[31] UNCRC (1989). The Convention on the Rights of the Child. UN General Assembly.

[32] UNESCO (2000). Impact of Child Health on Education in Developing Countries: Barrow and Lee data set.

[33] UNESCO, (2000). The Dakar Framework for Action. Paris: UNESCO.

[34] UNICEF, (2011). Children and Aids: Fifth Stocktaking Report. New York.

[35] UNICEF and Department of Social Development (2006). Guideline for Early Childhood Development Services. Republic of South Africa. 